\title{
GÊNERO, AUTOGINOGRAFIA E PERFORMATIVIDADE EM MARGARET SKINNIDER
}

Raimundo Sousa *

\section{Resumo}

Mediante análise da autobiografia da militante feminista e nacionalista Margaret Skinnider, atuante no processo de descolonização irlandesa, neste trabalho examina-se seu uso transgressivo da vestimenta na constituição performativa do gênero, sublinhando sua instrumentalização do vestuário em microrresistências operadas nos interstícios das tecnologias disciplinares que relegavam à mulher uma posição subalterna no nacionalismo militar. Atento ao modo como Skinnider jogava com padrões de vestuário, demonstrarei que a militante transgredia duplamente as normatividades de gênero, seja por uma condescendência estratégica na qual burlava códigos de feminilidade no ato mesmo de sua suposta iteração, seja pela prática da travestilidade, que lhe facultava uma constante flutuação entre os polos masculino e feminino.

Palavras-chave: Gênero, autoginografia, performatividade, Margaret Skinnider

\section{Abstract}

Gender, autoginography and performativity in Margaret Skinnider

Through the analysis of the autobiography of the feminist and nationalist militant Margaret Skinnider, who acted in Ireland's decolonization process, I examine in this paper her transgressive use of clothing in the performative constitution of gender, highlighting her instrumentalization of clothing in microrresistences operated in the openings of disciplinary technologies which relegated women to a subordinate position in the military nationalism. Attentive to the way Skinnider played with clothing patterns, I will demonstrate that the militant doubly transgressed gender normativity, both through a strategic condescendence in which she cheated codes of femininity in the very act of their supposed iteration, and through the practice of travestility, which favored a constant fluctuation between male and female poles.

Keywords: Gender, autoginography, performativity, Margaret Skinnider

\section{Resumen}

Género, autoginografía y performatividad en Margaret Skinnider

A través del análisis de la autobiografía de la militante feminista y nacionalista Margaret Skinnider, activa en el proceso de descolonización de Irlanda, en este trabajo examinase su uso transgresor del vestuario en la constitución performativa de género, enfati-

Faculdade de Letras, Universidade Federal de Minas Gerais (UFMG), Belo Horizonte, MG, CEP: 31270-901, Brasil.

Endereço eletrónico: raimundo_sousa@terra.com.br

Endereço postal: Rua Frederico Bracher Junior, 300, Ap. 902, bloco B, bairro Padre Eustáquio, Belo Horizonte, MG, CEP: 30720-000, Brasil. 
zando su instrumentalización del vestuario en microrresistencias en los intersticios de las tecnologías disciplinarias que relegan las mujeres a una posición subordinada en el nacionalismo militar. Consciente de cómo Skinnider juega con los estándares de vestuario, demuestro que la militante transgrede doblemente las normatividades de género, sea en una condescendencia estratégica en el que se burló de los códigos de la feminidad en el acto mismo de su supuesta iteración, sea en la práctica de la travestilidad, que le proporcionó una fluctuación constante entre los polos masculino y femenino.

Palabras clave: Género, autoginografía, performatividad, Margaret Skinnider

\section{A morte da autora}

Is the pen a metaphorical penis? [...] If the pen is a metaphorical penis, with what organ can females generate texts?

Sandra Gilbert E Susan Gubar

No célebre manifesto contra o biografismo, Roland Barthes (1968) propugnou uma hermenêutica centrada na intratextualidade, sublinhando a falência da instância autoral enquanto circunscrição da leitura ao anunciar retoricamente a «morte do autor». Seu argumento de que o autor morre tão logo nasce o texto desagradou à crítica feminista porque, ironicamente, no instante mesmo em que as mulheres começavam a conquistar espaço autoral, teóricos como Barthes minimizavam o valor da autoria. No contrafluxo dessa subtração estatuária do autor, o projeto intelectual feminista reivindicava agência para escritoras eclipsadas por um cânone androcêntrico, de modo que o deslocamento da figura autoral para a margem da cena literária colidia com uma agenda pautada exatamente na legitimação institucional e na afirmação política da autoria. Essa disjunção epistemológica ocorreu porque, ao universalizar uma acepção autoral que, a rigor, era masculina, o ensaísta francês não observou que a desigualdade de condições enunciativas entre homens e mulheres tinha como corolário um panorama cujo desgaste operacional do autor para a crítica masculinista contrastava frontalmente com a incipiência da autora para a sua congênere feminista. Por passar ao largo das assimetrias de gênero na criação literária, ao propalar a exaustão da categoria autor, o manifesto barthesiano ignorou, segundo Nancy Miller (1988), que a crise da autoria na crítica literária não poderia ser estendida à mulher escritora, dada a sua posição embrionária como figura autoral. Portanto, a ocorrência de um hipotético «autorricídio» teria, politicamente, implicações mais mutiladoras para as mulheres do que para os homens, pois, se para estes poderia redundar na obliteração de uma entidade ancestral, para aquelas implicaria a morte prematura da autora ainda em estágio fetal como figura institucionalizada.

Noutra formulação seminal para a teoria literária, Philippe Lejeune (1975), ao caracterizar a autobiografia como modelo de escritura e modo de leitura, 
encapsulou essa bidimensionalidade do gênero literário na acepção de pacto autobiográfico, vínculo contratual autor-leitor que estabeleceria a natureza autobiográfica de um texto e, por conseguinte, o modo como este se daria a ler. $\mathrm{O}$ pacto se firmaria quando da verificação de coincidência onomástica entre autor, narrador e personagem, que remeteria, em última instância, ao nome do signatário na capa do livro. Para tanto, o autor cumpriria as cláusulas contratuais referentes às convenções do gênero e o leitor, investido de autoridade policialesca, testaria a autenticidade da autobiografia na conferência da observância às cláusulas. Todavia, conforme Leigh Gilmore (1994), ao sustentar que a legitimação taxonômica da autobiografia e, portanto, a sua legibilidade como tal dependem da efetivação do pacto, o teórico francês exclui do gênero parte expressiva do legado autoescritural ${ }^{1}$ das mulheres, pois desconsidera a precariedade enunciativa de autoras despossuídas de legitimidade discursiva para estabelecerem o pacto devido a restrições sociais que as obrigavam à ocultação da autoria mediante o uso de pseudônimos - inclusive masculinos - ou a total omissão da assinatura autoral em publicações anônimas. Mesmo quando presente, a assinatura indicaria ausência por epitomizar a não-identidade da mulher em um ordenamento sociojurídico patrilinear que a submetia ao homem pelo patronímico. Portanto, a ênfase de Lejeune na assinatura autoral ignora que, historicamente, a autoria tem acepções distintas para homens e mulheres: para os primeiros, vincula-se a noções axiais como tradição, genealogia e afiliação; para as últimas, constitui o signo de sua heteronomia numa esfera literária historicamente balizada pelo monopólio masculino.

As ressalvas feministas à desatenção de Barthes e Lejeune para desigualdades de gênero na dimensão autoral dão mostras da inviabilidade de examinarmos autonarrativas de mulheres sob os protocolos de leitura desenvolvidos com enfoque na literatura de autoria masculina. De fato, a crítica biográfica tradicional presume uma noção de sujeito supostamente universal que, na verdade, consiste na universalização do homem branco europeu encarnado na figura de JeanJacques Rousseau e, ao tomar suas Confessions como paradigma da escrita autorreferencial moderna, assume, não raro, concepções masculinistas de sujeito, experiência vivencial e narrativa. Por isso, a crítica biográfica feminista tem-se dedicado a questões suscitadas na e pela literatura autoescritural de mulheres e, sob a premissa de que as especificidades dessa literatura demandam procedimentos analítico-interpretativos também específicos, tem engendrado conceitos e terminologias que favoreçam a sua devida exploração.

Neste artigo, utilizarei os termos autoescritura, autonarrativa e escrita de si para me referir, genericamente, a práticas textuais (i.e., autobiografias, autoginografias, memórias) que operam na tênue fronteira entre a factualidade e a ficção, convertendo possíveis fatos em artefatos, e constroem uma autorrepresentação do autor-personagem, que, inscrito simultaneamente como sujeito e objeto do discurso, forja uma imagem-de-si mediante convenções enunciativas como a escrita em primeira pessoa. 
Como reação ao atrelamento da autobiografia ao masculino pela crítica biográfica convencional, Domna Stanton (1984), em ensaio de grande repercussão, cunhou a nomenclatura autoginografia (autogynography) com vistas a designar um paralelo feminino para esse gênero literário. Nessa elaboração terminológica, a ensaísta faz um rearranjo no termo autobiografia, suprimindo a partícula bio (vida) como recusa à totalizante noção de narrativa de «uma vida» aí implicada. Embora a crítica convencional problematize essa fantasia de plenitude - como faz Pierre Bourdieu (1986) ao denominá-la «ilusão biográfica» -, a sua preservação da nomenclatura autobiografia acaba por reforçar indiretamente a noção de completude nela pressuposta, enquanto Stanton, nessa extração, promove uma contestação mais radical. No lugar de bio, a autora insere a partícula gino (mulher) com vistas a ressaltar, simultaneamente, que a mulher também escreve autonarrativas e que a sua composição autoescritural tem caráter disjuntivo numa lógica suplementar frente à perspectiva autobiográfica monolítica. Dessa maneira, a ensaísta não só empreende uma desmontagem - ou, mais apropriadamente, uma desconstrução - terminológica da autobiografia como também assinala que o gênero (genre) possui gênero (gender). Por conseguinte, a adoção de uma nomenclatura marcadamente feminista constitui uma forma de reconhecer as particularidades das autoescrituras de mulheres quanto às condições de produção, circulação e recepção.

A nomenclatura autoginografia tem operacionalidade como modo de sublinhar os aspectos diferencias das autonarrativas de mulheres, demandar uma postura analítico-interpretativa compatível com essas especificidades e, assim, competir para a expansão teórico-metodológica da crítica biográfica tradicional. Todavia, não se pretende classificar indistintamente como autoginografia todas as autonarrativas escritas por mulheres, pois isso implicaria sobrepor o gênero (gender) identitário ao gênero (genre) literário ao enquadrá-las em um único paradigma escritural, ignorando a heterogeneidade de obras inscritas em diferentes modelos e, portanto, delimitadas por regras e convenções distintas. Implicaria, ainda, reduzir a autoginografia a uma nomenclatura sobremaneira genérica que restringiria os modos de leitura dessas autoescrituras em vez de expandi-los. Uma vez que a ressalva feminista à crítica biográfica tradicional se atém ao fato de sua conceituação de autobiografia, masculinista por excelência, desconsiderar as especificidades escriturais das mulheres, a autoginografia é aqui tomada, stricto sensu, como equivalente feminino da autobiografia. Em adesão à epistemologia suplementar da crítica biográfica feminista, explorarei mais adiante essa nomenclatura ao proceder à análise de uma autoginografia. Antes, porém, farei uma breve discussão teórica sobre um conceito cuja utilização pode ser profícua para a abordagem desse gênero literário contrapontístico em relação à autobiografia. 


\section{Gênero e performatividade}

Bien loin que l'objet précède le point de vue, on dirait que c'est le point de vue qui crée l'objet.

Ferdinand Saussure

Em formulação arrojada para a sua época, Joan Riviere (1929), inspirada no caso de uma mulher pública cuja exibição hiperbólica de comportamentos «femininos» contrapesava as suas transgressões de gênero, declarou que a feminilidade "poderia ser assumida e usada como uma máscara» enquanto forma de negociação de papéis na injunção patriarcal. E concluiu: «O leitor pode então indagar [...] onde eu traço a linha divisória entre a feminilidade genuína e a «mascarada». Minha sugestão não é, contudo, que haja qualquer diferença [...]. São a mesma coisa» ${ }^{2}$ (Riviere 1929, 38). Essa intrigante sinonímia antecipou o desconstrutivismo ao sugerir que a feminilidade supostamente arremedada constitui, ela própria, uma simulação, pois não passa de uma apropriação estratégica de normatividades de gênero. Em desdobramento desse insight, Judith Butler (1990) argumenta que o gênero, longe de seguir um fluxo natural determinado biologicamente, constitui-se pela iteratividade de atos performativos que engendram ilusão de naturalidade, se obedientes às interpelações dos aparatos disciplinares, ou revelam a sua contingência como constructo social, se insubmissos o bastante para evidenciarem como a identidade é criada nas e pelas próprias «expressões» que supostamente a revelam. Se não há identidade de gênero prédiscursiva, a mesma cadeia de repetição que naturaliza códigos de gênero instituídos pode atuar inversamente no sentido de romper com a ilusão de estabilidade identitária. Donde o caráter disruptivo da travestilidade, na qual se subvertem representações de gênero e a própria equivalência entre sexo e gênero, já que a diferença entre a anatomia da/do drag e o gênero representado revela o caráter contingente e imitativo deste último.

Na senda de Butler, Sidonie Smith (1998) incorpora o conceito de performatividade à crítica biográfica feminista para enfatizar, em contraponto às leituras substancialistas, que na autoescritura a interioridade do «eu» supostamente apriorística à expressão autobiográfica constitui um efeito da própria urdidura narrativa. Tal conceituação reforça a tendência pós-virada linguística de ruptura com uma acepção documental da autonarrativa como registro de fatos referenciais em favor de uma mirada construcionista atenta à ficcionalidade implicada no ato composicional. De fato, a noção de performatividade rompe com a presunção de equivalência entre representação e referente ao assinalar o caráter ficcional da autonarrativa para além da oposição binária entre realidade e ficção. Afinal, pontua de forma inequívoca que o texto autoescritural, longe de ser uma

2 Tradução livre do autor. O mesmo sucede em todas as traduções de citações em língua estrangeira. 
codificação especular de um referente apriorístico numa relação de transparência entre o vivido e o narrado, consiste, antes, em um procedimento linguístico-discursivo no qual os significados são constituídos na e pela linguagem. Sob essa ótica, se considerarmos a proposição saussuriana de que é o ponto de vista que cria o objeto, a performance narrativa toma o referente como mote, mas, como ato de criação, produz a história de vida que supostamente reproduz.

Apesar de operatória para a crítica biográfica, a apropriação empreendida por Smith não explora devidamente o conceito de performatividade no que concerne à analogia entre performance corporal e performance textual. Ora, se, conforme Butler, o gênero é constituído mediante atos performativos, a autoescritura, na qualidade de ato performativo, também produz efeito de gênero. Em outras palavras, possui performatividade não apenas enquanto construção textual do sujeito, mas, mais especificamente, como construção de um sujeito sexualizado por ser uma das formas pelas quais este assume identidades de gênero; afinal, como vimos anteriormente, a propósito da autoginografia, o gênero (genre) possui gênero (gender). Uma vez que definir-se implica, em última instância, narrar-se, as autonarrativas, ao conferirem concretude à abstrata noção de identidade, permitem verificar como o autor-personagem se constrói como sujeito que negocia com códigos de masculinidade e/ou feminilidade instituídos. Por isso, a atenção para o gênero como performatividade, particularmente em autoginografias, favorece o exame de como os sujeitos se constituem em observância ou resistência aos ditames biopolíticos, como se verá no exercício de leitura que empreenderei a seguir, ao analisar a autoginografia da irlando-escocesa Margaret Skinnider, cuja apropriação performativa de paradigmas identitários masculinos e femininos favoreceu sua atuação numa das sublevações mais sangrentas do século XX.

\section{O gênero vestuário e o gênero como vestuário}

You're born naked, and the rest is drag.

Na colonização da Irlanda, o imperialismo inglês adotou uma economia geopolítica bidimensional de racialização do gênero e generização da raça ao instaurar um regime de representação bipolar que masculinizava o império e feminizava a colônia, a fim de naturalizar o vínculo colonial e chancelar a sua configuração assimétrica sob os álibis da complementaridade e hierarquia «naturais» entre os sexos, além de convencer os irlandeses de sua efeminação e, assim, mutilar seu potencial insurrecionário. Como a resistência é a contraface do poder, os irlandeses reagiram ao travar, de um lado, batalhas literais pela autonomização política e, de outro, batalhas simbólicas pela sua autorrepresentação. Todavia, por não ocuparem na dialética colonial as mesmas posições estatuárias que os colonizadores, precisaram fazê-lo sob limites discursivos circunscritos pelos últimos, de 
modo que a consubstanciação de uma identidade nacional pretensamente genuína dependeria, a rigor, da ambivalente dinâmica de contrassignificação na qual os estereótipos auferidos pelo discurso colonial seriam antes contrafeitos (via ressignificação) do que desfeitos (via desconstrução). Noutros termos, o anticolonialismo constituiu, no limite, um corolário ideológico do próprio colonialismo a que se contrapunha por reagir à economia maniqueísta que distinguia a virilidade imperial e a feminilidade colonial em semelhante maniqueísmo, instaurando rígidos códigos de gênero em um nacionalismo anticolonial fincado na radicalização de assimetrias entre homens e mulheres (cf. Sousa 2013).

Numa de suas insurreições mais contundentes, a Revolta da Páscoa de 1916, os irlandeses se valeram da instrumentalidade simbólica do catolicismo ao adotarem como paradigmas de gênero as figuras de Jesus e Maria, com vistas à naturalização de uma ideologia militarista pautada na concatenação entre o sacrifício másculo e a abnegação feminina. Assim, o rifle (dispositivo masculinizado, alusivo a valentia, sangue e protagonismo) e o rosário (dispositivo feminizado, alusivo a candura, lágrima e coadjuvação) balizaram seus respectivos paradigmas de hombridade e feminilidade. Se, para os homens, essa configuração dualista era opressiva por presumir que a ratificação da virilidade não prescindia, em nome de códigos civis, da exposição ao risco de morte, para as mulheres era mutiladora porque restringia sua agência no projeto de nação, sobretudo se ousassem defender a Irlanda antes com o rifle do que com o rosário. Se as mulheres constituíam um métron da hombridade dos homens na medida em que estes se provariam tão másculos quanto mais capazes de defendê-las, seu envolvimento militar não apenas desmantelava balizas de gênero como resultava em constrangimento para eles, que, afinal, deveriam provar sua masculinidade subestimada pelo império ao defender, com o próprio sangue, as suas compatriotas (cf. Sousa 2013).

Todavia, diversas mulheres tiveram beneplácito patriarcal para atuarem na revolta como despachantes porque capazes de passar insuspeitadamente pelas tropas inglesas. Sob seus vestidos, moças aparentemente inofensivas estabeleciam contato entre os postos distribuídos em Dublin, transportando desde mensagens confidenciais a armamentos. Porém, essas mulheres, autorizadas a colaborar apenas como não-combatentes, não ultrapassavam o cordon sanitaire entre a esfera masculina e a feminina e, portanto, não ameaçavam a configuração falocrática do projeto nacional. Se essas mulheres usavam a feminilidade como máscara, a militante Margaret Skinnider (1893-1971) explorou duplamente a potencialidade disruptiva da performatividade ao usar como máscara também a masculinidade. Em análise de sua autoginografia, Doing my bit for Ireland (1917), examinarei como a autora, mediante instrumentalização do vestuário na constituição performativa do gênero, teria trapaceado o monopólio masculino na luta armada para atuar também como combatente.

No limiar entre os registros autobiográfico e memorialístico, essa autoginografia extrapola enclaves categoriais ao hesitar entre a centralidade em Skinnider 
e na Revolta. A autora reforça essa indecidibilidade ao defini-la, simultaneamente, como «minha história», indicando nuclearidade do Eu, e «relato do que sei sobre a revolta», apontando a sublevação como epicentro da narrativa (Skinnider 1917, vii). Em leitura apressada, essa tensão dilemática entre o pessoal e o coletivo poderia ser tomada como esquizofrenia terminológica, mas, em análise atenta às condições de produção, constitui um índice da hesitação da mulher, numa sociedade androcêntrica, em posicionar-se como protagonista de sua própria história. Leonor Arfuch (2002), ao afirmar que, no contexto de formação de identidades nacionais, a escrita de si caracteriza-se, não raro, por uma trama na qual o individual é indiscernível do coletivo, apresenta um argumento coerente, mas passa ao largo das desigualdades de gênero. Ora, em um arranjo social que desencorajava as mulheres a se verem como protagonistas, não surpreende que a escrita autoginográfica de Skinnider chame a atenção pela posição ambígua da autora, cuja consciência de sua condição anódina, expressa já no título Doing my Bit for Ireland (Fazendo meu Bocadinho pela Irlanda), contrasta com o senso de individualidade que Lejeune (1975), ao tomar como paradigma autobiógrafos masculinos, atribui à escrita autobiográfica.

A autoginografia de Skinnider é heteróclita a padrões não apenas de gênero (genre) como também de gênero (gender). Filha de irlandeses, a militante feminista e nacionalista nascida na Escócia considerava a Irlanda a sua pátria e repudiava a violência perpetrada contra a ilha pelo império. Quando da fundação de clubes de artilharia dedicados ao preparo de mulheres escocesas para a defesa imperial, aprendeu a atirar com o intuito de enfrentar o próprio império, e o fez quando recrutada por Constance Markievicz, única mulher entre os líderes da Revolta, para colaborar na insurreição. Em sua viagem, trajava um modelito «feminino», composto de casaco e chapéu, mas, sob essa máscara de feminilidade, estava armada literalmente dos pés à cabeça:

Naquela noite, atravessei o Mar da Irlanda. Todos os passageiros haviam se dirigido aos seus aposentos, mas permaneci na coberta do navio. Inclinada para trás numa cadeira, usando meu chapéu como travesseiro, caí no sono. Foi um milagre eu ter despertado. No meu chapéu, levava para a Irlanda detonadores de bombas, e os fios estavam envoltos em mim, sob meu casaco. Por isso não quis ficar em um recinto onde [...] uma corrente elétrica pudesse explodi-los [os detonadores]. Mas a pressão, disseram-me quando cheguei a Dublin, é igualmente perigosa, e minha cabeça havia repousado pesadamente sobre eles a noite toda! (Skinnider 1917, 9-10).

A modéstia de Skinnider no título da obra é contradita pela ênfase no grande perigo corrido logo no início de sua missão. Essa contradição evidencia que, apesar de suas particularidades, a autoginografia não é de todo alheia ao sistema de convenções de uma escrita de si calcada na automonumentalização do autor, ainda que em observância ao horizonte de expectativas do público ávido por histórias de vida extraordinárias - no duplo sentido de incomuns e prodigio- 
sas. Por mais que tenha enfrentado perigos, Skinnider confere dramaticidade ao episódio, narrado à maneira de um romance de aventuras. Frente à dúplice tarefa de registrar a experiência vivida e fazê-lo de forma instigante, a autora tece uma narrativa «impura», para tomarmos de empréstimo a conceituação de François Dosse (2005) ao definir a biografia como «gênero impuro» devido à sua hibridez entre a factualidade e a ficção, já que contar uma vida implica conferir unidade a fragmentos mediante elaboração textual.

Na casa de Markievicz, Skinnider se surpreendeu com uma variedade de trajes teatrais que serviam tanto como figurinos para peças quanto como disfarces para figuras transgressivas no encalço da polícia, haja vista o episódio no qual um líder sindical escondido na casa conseguiu despistar os policiais que a revistaram:

Ao chegarem, depararam-se com um baile de máscaras [...]. Como aquele não era um ambiente provável para um agitador trabalhista, foram embora. Porém, a precaução os trouxe de volta na manhã seguinte [...]. Ficaram em vigília pela casa durante toda a manhã e tarde. Várias pessoas iam e vinham, dentre as quais um velho que mal conseguia caminhar e se apoiava no braço de uma mocinha. A polícia não prestou mais atenção nele do que nos demais, mas aquele era o líder trabalhista num dos disfarces do guarda-roupa teatral (Skinnider 1917, 11-12).

Ao identificar o guarda-roupa como manancial de personas, Skinnider fornece uma metáfora para a negociação com paradigmas identitários. Enquanto o armário metaforiza a «repressão» da identidade, o guarda-roupa remete a um repertório de identidades provisórias, na medida em que o exercício ético de decidir qual identidade assumir em cada ocasião é análogo ao procedimento estético de selecionar no guarda-roupa o traje adequado para cada contexto. Essa perspectiva não pressupõe a existência de «eus fictícios» que escamoteiam um «eu autêntico» e tampouco coaduna com a recorrente ideia de que possuímos identidades múltiplas e as mobilizamos em conformidade com cada situação. Diferentemente, indica, para retomarmos Butler (1990), que não há um núcleo interno subjacente à performance identitária, pois a identidade, longe de endógena, é forjada no próprio ato de sua aparente expressão. Assim, ao perceber que as roupas, para além de sua utilidade em encenações teatrais, tinham valência performativa em táticas de passing igualmente teatralizadas, Skinnider montou seu próprio guarda-roupa, que permitiria à voluntária, arregimentada para atuar como despachante, assumir também um segundo papel, ainda mais ousado:

Quando contei a Madame [Markievicz] que podia me passar por garoto, ainda que se tratasse de luta livre ou assobio, ela experimentou me colocar em traje de menino um uniforme dos Fianna. Deixou-me sob os cuidados de um dos seus rapazes, a quem explicou que eu era uma moça, mas que, como poderia ser preciso algum dia me disfarçar de garoto, ela queria verificar se eu seria capaz de escapar à detecção. Eu seria, 
supostamente, um dos Fianna de Glasgow. Saímos, juntámo-nos aos outros Fianna e caminhámos pelas ruas, assobiando canções rebeldes (Skinnider 1917, 20-23).

Skinnider atuaria, então, ora como mulher/despachante, ora como homem/ / fuzileiro, devendo ser «feminina» o suficiente para executar suas operações de espionagem e transporte clandestino sem levantar suspeitas e «masculina» o bastante para convencer seus companheiros de que era um deles. Nessa alternância de papéis, a troca de gênero (genre) vestuário constitui um rito de passagem que implica, também, mudança de gênero (gender) identitário: «Sempre que convocada para realizar um despacho», explica a autora, «tirava meu uniforme, punha meu vestido cinza e o chapéu, e saía [...] com minha mensagem. Ao retornar, eu me enfiava novamente no uniforme e me arregimentava ao pelotão de fuzilamento» (Skinnider 1917, 138).

A iteratividade dessa metamorfose engendra duas cadeias de repetição antitéticas, evidenciando como o gênero identitário, literalmente, vive de aparências, pois não apenas se constitui pelo gênero vestuário como ele próprio é um vestuá-

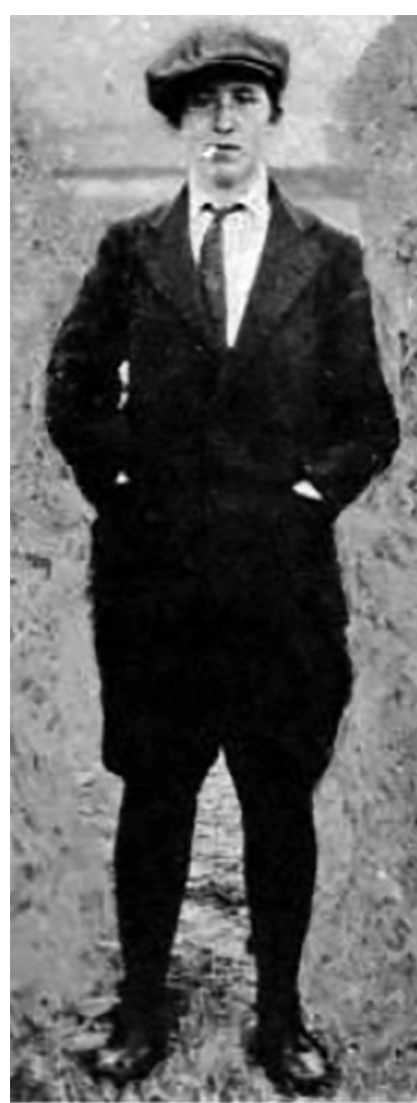

Figura 1. Masculinidade como máscara (Fonte: Skinnider, 1917, 21) rio enquanto inscrição cultural. Ao assumir transidentidades cambiantes numa constante flutuação entre as polaridades homem e mulher, Skinnider deixa entrever a instabilidade de categorias sociais cuja suposta diferença ontológica é forjada precariamente por meio de performances estilizadas. Como somos interpelados a exibirmos performances preestabelecidas que reiterem nossa inscrição em determinado padrão identitário, a (con)formação de nossa identidade constitui, em última análise, um gesto de arremedo que Skinnider radicaliza na medida em que o caráter paródico de sua performatividade põe à vista a natureza artificial do próprio gênero, como se nota na fotografia (Fig. 1) em que a ativista parodia o estereótipo de masculinidade, exibindo uma versão superlativa do masculino ao posar com as pernas entreabertas, as mãos enfiadas nos bolsos e um charuto na boca.

De igual modo, a forma como Skinnider veste a feminilidade como máscara dá mostras de como os repertórios de gênero vestuário do seu guarda-roupa lhe permitem constituir performativamente o gênero identitário e, assim, escapar ilesa de situações ameaçadoras. Ao cumprir uma de suas missões noturnas, agora «montada» como mulher, a ativista despertou a curiosidade de um policial que, no entanto, identificou-a como apenas uma jovem indefesa: 
Um policial veio lentamente em minha direção. Ele portava uma lanterna escura e, ao me avistar, acendeu-a no meu rosto. Olhou-me fixamente, mas nada disse. Decerto ele se perguntava o que uma moça decentemente vestida fazia naquela parte da cidade, àquela hora. Eu o fitei tanto quanto ele a mim. Eis que ele avistou meu cordão. Então, cogitei dar três safanões e, ao mesmo tempo, atirar pimenta na sua cara [...]. Porém, ele não reparou no cordão e seguiu adiante. Meu coração havia parado de bater. Agora recomeçava (Skinnider 1917, 51).

Chama a atenção nesse excerto a adoção de um ritmo narrativo mais acelerado, balizado por sentenças curtas e verbos de ação, como que para textualizar a atmosfera de tensão que a autora teria vivenciado e, assim, reproduzir uma experiência que, de fato, é criada no próprio ato da escrita. Por isso, Arfuch (2002), ao considerar o caráter fragmentário da identidade, contesta a noção de pacto autobiográfico na medida em que não há identidade entre autor e personagem na autobiografia, dada a não coincidência entre a experiência vivencial e sua elaboração textual. De todo modo, como a escrita de si constitui uma «biografia» cujo autor é sua própria fonte, interessa investigar menos a veracidade dos fatos narrados por Skinnider do que os efeitos de sentido produzidos em sua performance narrativa, com o cuidado de não tomá-la como registro especular. Afinal, como já argumentei noutros termos, a mimesis é, antes de tudo, uma poiesis.

Nessa passagem, como efeito da performance de gênero empreendida por Skinnider, a mesma máscara de feminilidade que intriga o policial o despista de examiná-la atentamente, pois a transgressão espaço-temporal é contrabalançada pelo vestuário, que no mapa conceitual do guarda a reposiciona em seu lugar de gênero como respeitável professora de classe média, como se nota na fotografia ao lado (Fig. 2). Pelo tom irônico de sua autodescrição como «uma moça decentemente vestida», Skinnider parece tão crítica quanto à natureza prescritiva da feminilidade que a utiliza como recurso, de sorte que a aparente reverência constitui uma forma de transgressão na qual, ao vestir a máscara, ela desmascara convenções. Assim, servindo-se da estética como transgressão, a ativista se mostra obediente aos preceitos de

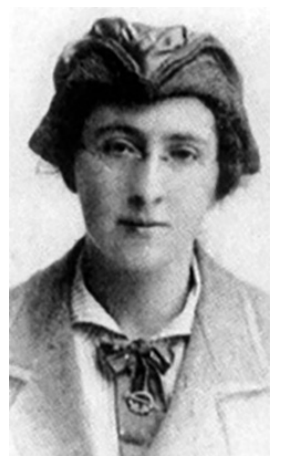

Figura 2. Feminilidade como máscara (Fonte: Skinnider, 1917, s.p.) gênero pela incorporação de uma feminilidade respeitável que, paradoxalmente, permite-lhe desrespeitá-la e, sob a aparente ingenuidade feminina, vigia sem ser notada, tal como quando passa despercebida por um policial: «Ele não prestou atenção em mim; eu era apenas uma moça de bicicleta. Mas o observei bem de perto» (Skinnider 1917, 95). Ao arremedar o sistema cultural hegemônico, Skinnider se engaja numa dinâmica de conformação e resistência na qual, apropriando-se dos repertórios disponíveis, joga com padrões de identidade em vez de se enquadrar acriticamente em posições-de-sujeito. Portanto, a forma como veste a feminilidade como máscara contradiz o argumento, sustentado por Luce Irigaray 
(1989), de que tal recurso evidencia o status da mulher como espetáculo, não como espectadora, como objeto de desejo, não como sujeito desejante. Para a teórica francesa, a máscara configura uma forma de objetificação na qual a mulher usufrui de alguma aquiescência social à custa da satisfação de fantasias masculinas e adequação a um sistema de valores que não o seu, anulando o seu próprio desejo. Ora, se, por um lado, a máscara pressupõe mise-en-scène para um espectador, por outro encerra um jogo de simulação e dissimulação que permite ver escondendo-se, como demonstra Skinnider.

O modo como a personagem se apropria performativamente do vestuário contraria a tendência do feminismo radical à vitimização da mulher pela identificação dos padrões estéticos como dispositivos de controle cuja convergência entre interesses capitalistas e patriarcais a aprisionaria à condição ornamental. Ao desconsiderar o potencial de agência da mulher na forma como (in)veste suas roupas, tal perspectiva incorre no mesmo sexismo patriarcal que a estereotipa como passiva, ingênua e vulnerável. Quando, no lugar de indagarmos o que as normas de gênero fazem das mulheres, reformulamos a questão para o que estas fazem com o que tais normas procuram fazer delas, encontramos resistências nas franjas das próprias normas, pois os significados que as mulheres atribuem ao vestuário não são necessariamente aqueles pensados pelos aparatos de controle. Esse uso performativo da feminilidade como (est)ética da transgressão calcada no uso criativo de padrões de vestuário em princípio normatizadores é patente na cena em que Skinnider se vale de um único adereço para induzir um rapaz a ajudá-la no reconhecimento do território onde se situaria o quartel:

Quando cheguei ao ponto onde imaginava que o paiol se localizava, tirei o meu lenço e o deixei voar - acidentalmente, é claro - sobre o muro. Um garoto que passava se ofereceu galantemente para resgatá-lo para mim. Por ser mulher e, naturalmente, curiosa, achei necessário me erguer sobre a ponta dos pés para vê-lo enquanto ele escalava o muro. $O$ terreno entre as duas paredes não havia sido pavimentado, mas era de terra macia. Vi o suficiente. Agradeci ao rapaz, coloquei meu lenço cuidadosamente no bolso, de modo a não incomodar mais ninguém, fazendo-o escalar os muros de Dublin, e segui meu caminho (Skinnider 1917, 40-41).

Pelo sarcasmo de sua narração e pela ironia com que se refere a estereótipos de gênero, a militante deixa claro que, ao invés de considerar a feminilidade uma essência da qual a mulher se vale quando conveniente, considera-a uma fabricação cultural que só produz efeitos de sentido pela repetição. Esse exemplo é sintomático de como a personagem exerce agência ao trapacear a ordem vigente mediante condescendência estratégica na qual, à primeira vista, atua como correia de transmissão da ideologia patriarcal pelo aparente reforço das normas. Ora, se não pode confrontar radicalmente o patriarcado, Skinnider empreende microrresistências ao assumir identidades provisórias nas quais o repertório vestuário, sob o aparente reforço de códigos de gênero, serve como recurso para a 
transgressão de limites físicos e simbólicos, resultando que suas performances subvertem a norma no ato mesmo de sua suposta iteração. Portanto, mesmo a adequação ao padrão de feminilidade pode ser disruptiva enquanto artificialidade calculada, pois, ao aparentemente se submeter aos códigos de gênero dominantes pelo vestuário «bem-comportado», Skinnider desnuda em seu vestuário a estrutura imitativa e contingente do gênero, embaralhando a polaridade entre conformação e resistência.

\section{Coda}

Transvestism is a space of possibility structuring and confounding culture: the disruptive element that intervenes, not just a category crisis of male and female, but the crisis of category itself.

Marjorie Garber

Se, por um lado, a vitimização da mulher, ao inscrevê-la como passiva frente à ingerência patriarcal, ratifica a própria ideologia falocêntrica que a sustenta, atribuir à mulher uma liberdade plena para jogar transgressivamente com as normatividades de gênero seria uma generalização perigosa, já que o meu foco investigativo incide sobre um caso bastante específico. Ao conceituar o gênero como vestuário, não procurei relativizar o impacto dessa construção social que nos constitui, mas, sim, pensar em possibilidades de negociar performativamente com padrões de feminilidade. Portanto, o exemplo de performatividade tratado neste artigo evidencia a estrutura contingente e imitativa do gênero na medida em que este não apenas se constitui pelo efeito da vestimenta como ele próprio é uma roupagem que assumimos, transgressivamente ou não, em nossas práticas sociais.

Inscrito no domínio da crítica biográfica feminista, este ensaio apresentou, mediante as noções de autoginografia e performatividade, algumas chaves de leitura para o exame de autonarrativas escritas, sobretudo, por mulheres. Uma vez que a conceituação de autobiografia, tal como definida por Lejeune, assumiu feição androcêntrica, a crítica da biografia feminista, ao adotar a nomenclatura autoginografia como seu «equivalente» feminino, visou preencher uma lacuna deixada pela crítica tradicional. Essa nomenclatura constitui uma forma de politizar simultaneamente os gêneros literário e identitário ao assinalar que as autonarrativas de mulheres possuem particularidades que requerem um tratamento específico, sem o qual correm o risco de serem subestimadas ou mesmo negligenciadas, como inegavelmente têm sido. Por seu lado, a noção de performatividade é operatória por ressaltar o caráter não especular das escritas de si ao concebê-las como performances que criam significados no próprio artifício da tessitura narrativa. A atenção para a performatividade do gênero (genre) também elucida a constituição performativa do gênero (gender), na medida em que a escrita de si 
figura entre as formas pelas quais o sujeito, em sua autorrepresentação, negocia com paradigmas de masculinidade e feminilidade instituídos.

Uma forma de explorar o gênero (genre) como espaço de constituição performativa do gênero (gender) consiste na percepção deste último como uma espécie de vestuário. Se tomarmos o guarda-roupa como metáfora do repertório de identidades provisórias que assumimos em nossas negociações sociais, a concepção do gênero como um vestuário assinala tanto sua não fixidez quanto sua artificialidade. Tentei desenvolver esse insight ao examinar como Margaret Skinnider, conforme narra em sua autoginografia, burlou o androcentrismo da agenda anticolonial irlandesa e tornou-se uma das figuras exponenciais da Revolta de 1916 graças à instrumentalidade do vestuário. Ao conceber a narrativa como performance, procurei examinar seus efeitos de sentido, sem incorrer no equívoco de tomá-la como registro transparente da experiência vivida ou na quimera de avaliar o índice de veracidade de cada relato. Assim, observei que Skinnider transgride duplamente as normatividades de gênero, quer pela apropriação estratégica que subverte os códigos de feminilidade no ato mesmo de sua aparente iteração ao usar a feminilidade como máscara, quer pelo cross-dressing, que lhe permite transitar entre os polos masculino e feminino, colapsando oposições binárias supostamente ontológicas. Esse exemplo de performatividade evidencia a estrutura contingente e imitativa do gênero na medida em que este não apenas se constitui pelo efeito da vestimenta como ele próprio é uma roupagem que assumimos, transgressivamente ou não, em nossas práticas sociais. Portanto, embora este ensaio, enquanto exercício teórico e exploratório incipiente, não permita alinhavar conclusões categóricas, pensar o gênero como vestuário pode «dar muito pano para manga».

\section{Referências Bibliográficas}

Arfuch, Leonor. 2002. El espacio biográfico: Dilemas de la subjetividad contemporánea. Buenos Aires: Fondo de Cultura Económica.

Barthes, Roland. 1968. «La mort de l'auteur». Manteia, 5: 12-17.

Bourdieu, Pierre. 1986. «L'illusion biographique». Actes de la Recherche en Sciences Sociales, 62 / 63: 69-72. DOI: https: / / doi.org/10.3406/arss.1986.2317

Butler, Judith. 1990. Gender trouble: feminism and the subversion of identity. Nova Iorque: Routledge.

Dosse, François. 2005. Le Pari biographique: Écrire une vie. Paris: La Découverte.

Gilmore, Leigh. 1994. Autobiographics: A Feminist Theory of Women's Self-Representation. Ithaca: Cornell University Press.

Irigaray, Luce. 1989. «Masquerade reconsidered: Further thoughts on the female spectator». Discourse 11(1): 42-54. URL estável: http:/ / www.jstor.org/stable/ 41389107.

Lejeune, Philippe. 1975. Le pacte autobiographique. Paris: Editions du Seuil.

Miller, Nancy K. 1988. Subject to Change: Reading Feminist Writing. Nova Iorque: Columbia University Press. 
Riviere, Joan. 1929. «Womanliness as masquerade». The International Journal of Psychoanalysis 10: 303-313.

Skinnider, Margaret. 1917. Doing my bit for Ireland. Nova Iorque: The Century CO.

Smith, Sidonie. 1998. «Performativity, autobiographical practice, resistance». In Women, Autobiography, Theory: a Reader, editado por Sidonie Smith, e Julia Watson, 108-115. Madison: University of Wisconsin Press.

Sousa, Raimundo E. S. 2013. «Da Feminização à Remasculinização: Gênero e Raça na Dialética Angloirlandesa». Dissertação de Mestrado em Estudos Literários, Faculdade de Letras, Universidade Federal de São João del-Rei.

Stanton, Domna. 1984. «Autogynography: Is the Subject Different?» In The Female Autograph: Theory and Practice of Autobiography from the Tenth to the Twentieth Century, editado por Domna Stanton, 5-22. Nova Iorque: New York Literary Forum.

Raimundo Expedito dos Santos Sousa. Doutorando em Teoria da Literatura e Literatura Comparada na Universidade Federal de Minas Gerais (UFMG), com financiamento da Fundação de Amparo à Pesquisa do Estado de Minas Gerais (FAPEMIG); mestre em Estudos Literários pela Universidade Federal de São João del-Rei (UFSJ), com financiamento da Capes / REUNI.

Artigo recebido em 29 de setembro de 2016 e aceite para publicação em 23 de outubro de 2016. 
